\title{
Word-Finding Behaviors of Discourse Production Task in Healthy Elderly Adults
}

\author{
Hyunjoo Choi \\ Department of Communication Disorders, Korea Nazarene University, Cheonan, Korea
}

\author{
Received: September 6, 2020 \\ Revised: October 5, 2020 \\ Accepted: October 6, 2020 \\ Correspondence: \\ Hyunjoo Choi, PhD \\ Department of \\ Communication Disorders, \\ Korea Nazarene University, \\ 48 Wolbong-ro, Seobuk-gu, \\ Cheonan 31172, Korea \\ Tel: +82-41-570-1677 \\ Fax: +82-41-570-7846 \\ E-mail: hjchoi@kornu.ac.k
}

\begin{abstract}
Purpose: The purpose of this study is to investigate whether there is a difference in word-finding behaviors in the discourse production task according to the age group of the elderly, from the young-old to the old-old. Methods: A total of 103 healthy elderly adults (55 to 85 years old) participated in this study. To exanimation of word-finding behaviors in the discourse, a picture description task was used. And, as the word naming task, the confrontational naming and the verbal fluency tasks were used. Results: First, according to the age group, the difference in the ratio of wordfinding behaviors were statistically significant. Especially, there were significant differences according to the age group of the elderly in word-finding behaviors of repetitions, empty words, insertions, and delays. Second, the difference in performances of word naming task (Korean version-Boston Naming Test and semantic verbal fluency) according to the age group of the elderly was found to be significant. Finally, the performance of the word naming task showed a significant correlation with the ratio of word-finding behaviors in the discourse production task. Conclusion: This study has clinical significance in that it analyzed various word-finding behaviors in a natural environment where the problem of naming appears in elderly adults.
\end{abstract}

Key Words: Discourse production, Elderly, Naming, Word-finding behaviors.

\section{INTRODUCTION}

노화로 인한 인지기능 저하는 노인들의 이름대기 능력에 손 상을 주며, 이러한 이름대기 능력의 저하는 노년층을 대상으로 한 언어장애 연구 중 가장 많은 비중을 차지한다(Kim \& Kim, 2009). 노화로 인한 이름대기 능력의 변화는 작업기억(working memory)과 주의력(attention)의 저하, 처리 효율성(processing efficiency)의 감소로 인한 정보 인출의 어려움 등이 원인인 것 으로 알려져 있다. 지금까지 노화로 인한 이름대기의 어려움과 관련된 연구들은 대면이름대기(confrontational naming)나 구어 유창성(verbal fluency) 과제와 같이 단어 인출 능력을 평가한 연 구들이 대부분이다(Bruda, 2010; Kim \& Kim, 2009). 이러한 과제 중 사물이나 그림을 보고 해당 사물의 이름을 말하는 대면 이름대기 검사는 가장 널리 사용되어 왔으며(Schmitter-Edgecombe et al., 2000), 이러한 과제로 평가한 연구들의 결과는 노 화로 인해 이름대기 능력이 저하된다는 연구와 보존된다는 연

(c) This is an Open Access article distributed under the terms of the Creative Commons Attribution Non-Commercial License (https://creativecommons.org/licenses/by-nc/4.0) which permits unrestricted non-commercial use, distribution, and reproduction in any medium, provided the original work is properly cited.
구가 혼재한다(Choi, 2014). 이렇듯 노인들의 대면이름대기 수 행에 관련된 연구 결과가 서로 일치하지 않는 이유는 연구마다 교육년수, 연령에 따른 목표 어휘의 친숙성(familiarity) 등에 차이가 있으며, 이러한 변수들이 이름대기 수행에 영향을 미치 기 때문이다(Schmitter-Edgecombe et al., 2000). 실제로 가장 많이 사용되는 표준화된 대면이름대기 검사인 The Boston Naming Test (Kaplan et al., 1983) 수행의 종단연구 결과 노년 층의 경우 10 년마다 약 $2 \%$ 씩 이름대기 능력이 감소하는 것으로 알려져 있다(Connor et al., 2004). 그러나 이러한 대면이름대기 검사들은 연령에 따른 정확도가 제한적이며(Mortensen et al., 2006), 고학력자들의 경우 이러한 검사들의 민감도가 낮은 것 으로 알려져 있다(Connor et al., 2004). 다음으로 구어 유창성 검사는 어휘목록(lexicon)과 의미기억에 있는 정보를 전략적으 로 탐색, 인출하는 능력을 알아보는 검사로, 주어진 시간(주로 1 분)안에 특정 의미 범주(semantic category)와 특정 음소 (phoneme)로 시작되는 어휘를 산출하게 하는 과제이다(Baldo et al., 2006). 노년층의 구어 유창성 과제 수행 능력은 의미기억 및 인지처리과정의 효율성 저하로 인하여 제한된다고 알려져 있다(Kang et al., 2000). 
노년층을 대상으로 한 단어산출 평가는 대부분 대면이름대 기나 구어 유창성 과제와 같이 단어 인출 능력을 평가하는 방 법에 의존하지만 이러한 방법이 적절한지에 대해서는 논란의 여지가 많다(Schmitter-Edgecombe et al., 2000). 그 이유는 이러한 과제는 단어 수준의 반응을 요구하며 이는 일상적인 대 화의 흐름 속에서 전형적으로 발생하는 단어산출의 곤란 상황 을 실제적으로 반영하기 어렵다(German, 1991). 앞에서도 언 급했듯이 대면이름대기와 같은 과제에서 노년층의 수행이 제한 되는가에 대한 연구 결과도 일치하지 않을 뿐 아니라 이러한 과 제로 노년층이 겪는 일상생활에서 나타나는 단어산출의 어려움 을 검출하는 것도 불가능하다(Goulet et al., 1994). 따라서 일부 연구자들은 자발화와 같은 담화(discourse) 상황에서 단어찾기 기술을 평가할 필요가 있다고 주장한다(Orange \& Purves, 1996; Schmitter-Edgecombe et al., 2000). 담화 상황에서의 단어찾기 능력을 평가하는 것은 단어산출의 문제가 나타나는 자연스러 운 환경을 반영할 뿐 아니라 다양한 유형의 단어찾기 행동 (word-finding behaviors)을 분석할 수 있다는 장점을 가진다 (Orange \& Purves, 1996). 이와 관련하여 노년층의 구어 유창 성 과제와 담화 과제에서의 단어찾기 행동을 분석하여 비교한 Heller \& Dobbs(1993)는 담화 상황에서 보다 다양하고 많은 단어찾기 행동이 산출되기 때문에 담화 상황에서의 이름대기 평가가 필요함을 주장하였다.

단어 찾기의 문제는 자발화에서 유창성(fluency)의 방해 및 붕괴로 나타나는데, 이는 불완전한 단어 지식, 단어 인출 과정 에서의 오류, 단어 생성을 위한 시간 지연을 반영하며, 다양한 단어 찾기 행동으로 드러난다(Faust et al., 1997). 이러한 단어찾 기 행동은 불특정, 무의미 단어(nonspecific empty word), 삽입 어(time fillers or filled pauses), 연장(delays or silent pauses), 에두르기(circumlocation), 언어 형성을 위한 메타언어적 언급 (metalinguistic comments), 대치(substitutions), 단어 삽입어 (utterance filler or word filler), 반복(repetitions), 문장 재구성 (statement reformulations) 등으로 분류된다(Tingley et al., 2003). 단어찾기 행동은 연구에 따라 다양하게 측정되어 왔다. Schmitter-Edgecombe et al.(2000)의 연구에서는 단어찾기 행 동을 대치, 단어 재구성(word reformulations), 반복, 무의미어, 삽입어, 첨가(insertions), 연장으로 분석하였으며, Boyle(2014) 은 Schmitter-Edgecombe et al.(2000)의 분석 변수를 기초로 대치를 의미착어(verbal paraphasia), 음운착어(phonemic paraphasia), 신조어(neologism)로 세분화하여 분석하였다. 다음으로 한국어 사용자를 대상으로 한 Baik(2013)의 연구에서는 Schmitter-Edgecombe et al.(2000)의 단어찾기 행동에 숨(breath sound)을 추가하여 분석하였다. 노년층의 단어찾기 행동 특성 을 분석한 연구들의 결과를 종합하면 우선, 청년층과 노년층의
단어찾기 행동을 비교한 Schmitter-Edgecombe et al.(2000)의 연구에서는 노년층의 경우 청년층에 비해 대치, 단어 재구성, 무의미어의 비율이 높은 것으로 나타났다. 다음으로 단어 삽입 어(lexical fillers)가 연령의 증가에 따라 유의하게 많이 산출되 고(Cheung \& Kemper, 1992; Ha et al., 2009), 자발화에서 불명 료한 단어 사용, 애매한 참조 및 에두르기가 증가하며(Obler \& Albert, 1981), 대치와 심(pause)이 증가하는 것(Baik, 2013)으로 알려져 있다.

현재까지 노년층을 대상으로 한 담화산출 과제에서의 단어 찾기 행동 분석을 시도한 국내 연구들은 일부의 행동에 국한되 어 분석하거나 노년층을 하나의 집단으로 구성하여 청년층과 의 비교를 통한 결과를 제시하고 있다. 그러나 다양한 단어찾기 의 행동이 연령의 증가에 따라 다른 양상을 나타내기도 하며, 이러한 담화를 통한 단어찾기 행동의 특성이 대면이름대기나 구어 유창성 과제와 같은 이름대기 과제와 비교하여 어떠한 유 용성을 가지는지에 대한 고찰이 필요하다. 노화로 인한 단어찾 기의 어려움은 노년층의 가장 주된 호소로 자연스러운 상황에 서 단어찾기 행동을 평가하는 것은 임상적으로 대단히 중요하 다. 따라서 본 연구에서는 연소노인부터 고령노인에 이르는 연 령 집단 별 노년층을 대상으로 그림설명 과제를 통한 다양한 단어찾기 행동의 특성을 분석하여 연령에 따른 차이를 비교하 고, 이러한 결과들과 대면이름대기, 구어 유창성 과제 사이의 관련성을 살펴보는 것을 목적으로 하였다.

\section{MATERIALS AND METHODS}

\section{연구 대상}

본 연구는 55 세에서 85 세까지의 노년층 103 명을 대상으로 하였다. 노년층의 기준은 연구자와 연구에 따라 차이가 있으나, 비교적 연령이 낮은 연소노인(young-old)을 포함시킨 연구들 은 55세 이상을 지칭하는 경우가 많으며(Neugarten, 1974), 고 용상 연령차별금지 및 고령자고용촉진에 관한 법률」 제 2 조제 1 호에 따르면 고령자를 55세 이상인 사람으로 정의하고 있다. 연 구 대상자의 선정기준은 다음과 같다: 1) 한국어를 모국어로 사용하고, 2) 한국판간이정신상태 검사(Korean version of Mini-Mental State Examination, K-MMSE) (Kang, 2006) 점 수가 연령 및 교육정도의 규준과 비교하여 -1SD (16th percentile) 이상으로 정상범주에 속하며, 3) 실어증 선별검사(Screening Test for Aphasia and Neurologic-Communication Disorders, STAND) (Kim et al., 2009)의 하위검사 중 '듣고 이해하 기'에서 어려움이 없고, 4) 단축형노인우울척도(Short form Geriatric Depression Scale, SGDS) (Cho et al., 1999) 점수가 8점 이하로 우울증이 없으며, 5) 신경·정신과적 과거 병력이 없 
고, 6) 과제를 수행하는 데 요구되는 시, 청각 능력을 가진 자였 다. 50대에서 90 대까지의 노화에 따른 이름대기 능력을 비교한 Verhaegen \& Poncelet(2013)에 따르면 이름대기의 어려움은 70대 이상에서 나타난다. 이를 근거로 본 연구의 연령 집단은 Hummert et al.(1995)의 기준에 따라 55세 이상부터 60대의 연 소노인(young-old), 70대의 중간노인(middle-old), 80대의 고 령노인(old-old)으로 구분하였다.

세 집단의 연령, 교육년수, $\mathrm{K}-\mathrm{MMSE}$ 점수의 평균 및 표준편 차는 Table 1에 제시하였다. 집단 간 성비에 차이가 있는지 알 아보기 위하여 카이제곱 $\left(\chi^{2}\right)$ 분석을 실시한 결과 집단에 따른 성비의 차이는 유의하지 않았다 $\left(\chi^{2}=3.127\right)$. 또한, 집단에 따른 교육년수 및 K-MMSE 점수에 차이가 있는지 알아보기 위하여 일원분산분석(one-way analysis of variance)을 실시한 결과 교 육년수 $(\mathrm{F}=5.515)$ 와 $\mathrm{K}-\mathrm{MMSE}$ 점수 $(\mathrm{F}=3.457)$ 에서의 집단 간 차이가 유의한 것으로 나타났다. 집단 간의 차이에 따른 사후분 석(Scheffe test) 결과, 교육년수에서 연소노인과 중간노인, 연소 노인과 고령노인 사이의 차이는 유의하였으나 중간노인과 고령 노인 사이의 차이는 유의하지 않은 것으로 나타났으며, $\mathrm{K}-$ MMSE 점수는 연소노인과 중간노인, 중간노인과 고령노인 사 이의 차이는 유의하지 않았으나 연소노인과 고령노인의 차이는 유의한 것으로 나타났다.

\section{연구 도구}

\section{담화산출 과제}

단어찾기 행동을 평가하기 위한 담화산출 과제로 그림설명 과제를 사용하였다. 그림설명 과제를 통한 평가는 대상자의 담 화산출 능력의 변화를 민감하게 반영할 수 있을 뿐만 아니라 그림이 지속적으로 제시되기 때문에 노화 등으로 인한 기억장 애의 영향이 적고, 대화와 같은 비구조화된 담화산출 과제에 비해 분석이 용이하다는 장점을 가진다(Duong et al., 2003). 본 연구에서는 파라다이스 한국판 웨스턴 실어증 검사(Paradise Korean version-Western Aphasia Battery, K-WAB) (Kim \& $\mathrm{Na}, 2001)$ 에 포함된 '해변가' 그림과 Boston Diagnostic Aphasia Examination (BDAE) (Goodglass et al., 2001)의 Boston
Cookie-Theft picture를 사용하였다. 담화산출을 통한 단어찾 기 행동 유형과 분석 기준은 Schmitter-Edgecombe et al. (2000)의 연구를 기초로 하였다. 이들의 단어찾기 행동은 글로 벌 지수(global index)와 특정 단어찾기 행동으로 구성되며, 특 정 단어찾기 행동은 대치(substitutions), 단어 재구성(word reformulations), 반복(repetitions), 무의미어(empty words), 삽입 어(time fillers), 첨가(insertions), 연장(delays)의 일곱 가지로 분류된다. 이 단어찾기 행동은 Test of Word-Finding in Discourse (TWFD) (German, 1991)의 분석기준으로 이름대기에 어려움을 가지는 대상자들의 단어찾기 행동을 민감하게 검출 할 수 있는 척도인 것으로 알려져 있다(German \& Glasnapp, 1990). 본 연구에서 사용된 단어찾기 행동의 구체적인 설명 및 예시는 Appendix에 제시하였다. 담화산출 과제의 분석을 위하 여 발화 구분은 Kim et al.(2012)의 기준을 따랐으며, 단어찾기 비율에 대한 정규화(normalization)를 위하여 노년층의 담화산 출 분석에 유용한 척도로 알려져 있는 어절 분석 방법(Jin et al., 2016)을 이용하여 전체 어절 중 특정 단어찾기 행동을 포함한 어절의 비율인 어절 당 단어찾기 행동 비율 분석을 사용하였 다. 어절 분석은 Yi(2015)의 기준을 따랐다.

\section{단어 이름대기 과제}

단어 이름대기 과제 중 대면이름대기 과제로는 한국판 보스 톤 이름대기 검사(Korean version-Boston Naming Test, K$\mathrm{BNT}$ ) (Kim \& Na, 1997)를 사용하였다. K-BNT는 국내에서 가장 널리 사용되는 이름대기 검사로 60 개의 흑백 선화로 표현 된 명사의 이름을 말하도록 하는 과제이다. 본 연구에서는 대 상자가 단서 없이 자발적으로 산출한 이름대기 정반응률(\%)을 산출하였다.

구어 유창성 과제는 집행기능 중 범주별 어휘 생성 능력을 평가하는 검사로(Baldo et al., 2006), 본 연구에서는 한국판 통 제단어연상검사(Korean version of Controlled Oral Word Association Test, K-COWAT) (Kang et al., 2000)를 사용하였 다. K-COWAT는 의미 유창성(semantic fluency) (동물, 가게물 건)과 음소 유창성(phonemic fluency) ('ᄀ', 'O', '’으로 시작되 는 낱말)으로 구성되어 있으며, 1 분 동안 가능한 많은 범주별

Table 1. Demographic characteristics of participants by elderly group

\begin{tabular}{|c|c|c|c|c|}
\hline & Young-old $(\mathrm{n}=32)$ & Middle-old $(\mathrm{n}=32)$ & Old-old $(\mathrm{n}=39)$ & $p$ \\
\hline Gender (male: female) & $12: 20$ & $10: 22$ & $20: 19$ & 0.209 \\
\hline Age (yr) & $62.63(4.72)$ & $76.38(2.41)$ & $82.77(1.72)$ & $<0.001^{* * *}$ \\
\hline Education level (yr) & $10.56(3.79)$ & $7.28(4.07)$ & $8.56(4.08)$ & $0.005^{* *}$ \\
\hline K-MMSE score & $26.44(1.59)$ & $25.41(2.59)$ & $24.82(3.19)$ & $0.035^{*}$ \\
\hline
\end{tabular}

${ }^{*} p<0.05,{ }^{* *} p<0.01,{ }^{* *} p<0.001$. Values are presented as mean (standard deviation). K-MMSE: Korean version of Mini-Mental State Examination 
단어를 산출하도록 하는 과제이다. 본 연구에서는 대상자가 1 분 동안 적절히 산출한 동물 수, 가게물건 수, 음소 유창성 과제의 총 산출 수를 사용하였다.

\section{연구 절차}

모든 검사는 방해를 받지 않는 조용한 장소에서 일대일로 진 행되었다. K-BNT와 K-COWAT는 표준화된 매뉴얼에 따라 검 사를 진행하였다. 그림설명 과제는 기존의 연구(Jin et al., 2016) 를 바탕으로 진행하였다. 우선, 대상자의 전면에 A4용지 사이 즈의 그림을 제시하고 "이 그림을 잘 보시고, 그림의 내용을 자 세하게 설명해주세요”라고 지시하였다. 그림설명 과정에서 대상 자의 반응을 유도하기 위하여 “더 설명하실 내용은 없으세요?" 라는 촉구 이외의 다른 개입은 하지 않았다. 대상자의 모든 반 응은 녹음 후 즉시 전사하였으며, 한 그림 당 30초 이상의 발화 만을 분석 대상으로 하였다. 전사된 발화를 바탕으로 글로벌 지수 및 대치, 단어 재구성, 반복, 무의미어, 삽입어, 첨가, 연장 의 일곱 가지 특정 단어찾기 행동을 분석하였다. 평가자 간 신 뢰도(reliability between judge)를 평가하기 위하여 전체 자료 의 $15 \%$ 를 추출하여 1 급 언어재활사 국가자격증과 언어병리학 석사학위 소지자인 제2평가자가 단어찾기 행동을 분석하였고, 평가자 간 일치율은 $94.08 \%$ 로 나타났다.

\section{통계 분석}

본 연구에의 모든 통계분석은 Statistical Product and Service Solution 22.0 (SPSS version 22.0; IBM Corp., Armonk, NY, USA) 프로그램을 사용하였다. 우선, 연소노인, 중간노인, 고령노인의 집단에 따른 단어찾기 행동의 글로벌 지수와 특정 단어찾기 행동의 비율, 이름대기 수행에 차이가 유의한지 알아 보기 위하여 교육년수를 공변량으로 한 다변량분석(multivariate analysis of variance)을 실시하고, 집단에 따른 차이가 유 의한 경우 Bonferroni 방법을 이용한 사후분석을 실시하였다. 다음으로 노인의 단어찾기 행동의 글로벌 지수와 특정 단어찾 기 행동의 비율, 단어 이름대기 수행 사이에 유의한 상관이 있
는지 알아보기 위하여 교육년수를 제어변수로 한 편상관분석 을 실시하였다.

\section{RESULTS}

\section{연령 집단에 따른 단어찾기 행동의 수행 차이}

연소노인, 중간노인, 고령노인의 담화산출 과제에서의 단어 찾기 행동 산출 비율의 기술 통계치를 Table 2에 제시하였다. 다음으로 연령 집단에 따른 단어찾기 행동 산출 비율에 차이 가 있는지 알아보기 위하여 교육년수를 공변량으로 한 다변량 분석 결과 Wilks 람다값은 0.628 이었으며, 집단에 따른 차이가 유의한 것으로 나타났다 $(\mathrm{F}=2.366, p<0.001)$. 단어찾기 행동 별로 산출 비율의 차이를 살펴보면 글로벌 지수 $(\mathrm{F}=7.659)$, 반 복 $(\mathrm{F}=3.551)$, 무의미어 $(\mathrm{F}=5.395)$, 첨가 $(\mathrm{F}=4.994)$, 연장 $(\mathrm{F}=$ 3.161)은 연령 집단 간 차이가 유의한 것으로 나타났으며, 대치 $(\mathrm{F}=2.211)$, 단어 재구성 $(\mathrm{F}=0.228)$, 삽입어 $(\mathrm{F}=1.969)$ 는 집단 간 차이가 유의하지 않은 것으로 나타났다. 또한, 연령 집단 간 유의한 차이를 보였던 단어찾기 행동의 산출 비율이 어느 집단 간의 차이에 기인하였는지 알아보기 위하여 사후분석을 실시 한 결과 글로벌 지수, 무의미어, 첨가의 경우는 연소노인과 중 간노인, 연소노인과 고령노인의 차이가 유의하였으며, 반복은 연소노인과 고령노인, 중간노인과 고령노인과의 차이가, 마지막 으로 연장은 연소노인과 고령노인의 차이만 통계적으로 유의 한 것으로 나타났다.

\section{연령 집단에 따른 단어 이름대기 과제의 수행 차이}

연소노인, 중간노인, 고령노인의 단어 이름대기 과제 수행의 기술 통계치를 Table 3에 제시하였다. 다음으로 연령 집단에 따 른 단어 이름대기 과제 수행에 차이가 있는지 알아보기 위하여 교육년수를 공변량으로 한 다변량분석 결과 Wilks 람다값은 0.684 였으며, 집단에 따른 차이가 유의한 것으로 나타났다 $(\mathrm{F}=$ $5.015, p<0.001)$. 단어 이름대기 과제별 수행 차이를 살펴보면 $\mathrm{K}-\mathrm{BNT}$ (F = 8.371), 의미 유창성(동물) $(\mathrm{F}=6.117)$, 의미 유창

Table 2. Descriptive statistics in ratios of word-finding behaviors by elderly group

\begin{tabular}{lcccc}
\hline & Young-old $(\mathrm{n}=32)$ & Middle-old $(\mathrm{n}=32)$ & Old-old $(\mathrm{n}=39)$ & $p$ \\
\hline Ratio of global index & $12.12(6.48)$ & $17.12(4.73)$ & $18.85(7.45)$ & $0.74(0.92)$ \\
Ratio of substitutions (\%) & $0.36(0.75)$ & $1.03(1.22)$ & $1.43(1.39)$ & 0.115 \\
Ratio of word reformulations (\%) & $1.31(1.46)$ & $1.50(1.39)$ & $3.54(2.55)$ & 0.797 \\
Ratio of repetitions (\%) & $2.26(1.89)$ & $2.32(2.27)$ & $4.77(4.00)$ & $0.032^{*}$ \\
Ratio of empty words (\%) & $2.64(1.99)$ & $5.98(3.97)$ & $2.27(2.38)$ & $0.006^{* *}$ \\
Ratio of time fillers (\%) & $2.97(2.93)$ & $1.76(1.63)$ & $3.18(2.22)$ & 0.145 \\
Ratio of insertions (\%) & $1.64(1.46)$ & $2.93(1.71)$ & $3.00(4.58)$ & $0.009^{* *}$ \\
Ratio of delays (\%) & $0.90(1.63)$ & $1.72(2.53)$ & $0.047^{*}$ \\
\hline
\end{tabular}

${ }^{*} p<0.05,{ }^{* *} p<0.01,{ }^{* * *} p<0.001$. Values are presented as mean (standard deviation) 
Table 3. Descriptive statistics in performances of K-BNT and verbal fluency test by elderly group

\begin{tabular}{lcccc}
\hline & Young-old $(\mathrm{n}=32)$ & Middle-old $(\mathrm{n}=32)$ & Old-old $(\mathrm{n}=39)$ & $p$ \\
\hline K-BNT (\%) & $83.65(11.89)$ & $75.93(9.76)$ & $70.51(14.05)$ & $13.18(3.96)$ \\
Semantic fluency (animal) & $17.03(5.34)$ & $13.75(2.93)$ & $13.79(4.46)$ & $<0.001^{* * *}$ \\
Semantic fluency (market) & $20.53(5.14)$ & $15.19(4.58)$ & $19.69(8.39)$ & $0.003^{* *}$ \\
Phonemic fluency & $25.34(10.59)$ & $19.53(8.39)$ & 0.191 \\
\hline
\end{tabular}

${ }^{*} p<0.05,{ }^{* *} p<0.01,{ }^{* *} p<0.001$. Values are presented as mean (standard deviation). K-BNT: Korean version-Boston Naming Test

Table 4. Result of correlation in analysis in ratio of word-finding behaviors, K-BNT, and verbal fluency test

\begin{tabular}{|c|c|c|c|c|c|c|c|c|c|c|c|c|}
\hline & GI & Sub & WR & Rep & EW & $\mathrm{TF}$ & Ins & Del & K-BNT & SF (a) & $\mathrm{SF}(\mathrm{m})$ & $\mathrm{PF}$ \\
\hline$\overline{\mathrm{GI}}$ & 1 & $0.265^{* *}$ & 0.128 & $0.355^{* * *}$ & $0.551^{* * *}$ & $0.396^{* * *}$ & $0.501^{* * *}$ & $0.554^{* * *}$ & $-0.475^{* * *}$ & $-0.471^{* * *}$ & $-0.407^{* * *}$ & $-0.318^{* *}$ \\
\hline Sub & & 1 & 0.026 & 0.168 & 0.030 & 0.063 & 0.134 & 0.035 & 0.092 & -0.033 & -0.056 & -0.032 \\
\hline WR & & & 1 & $-0.196^{*}$ & -0.179 & -0.036 & $-0.198^{*}$ & $-0.198^{*}$ & -0.128 & -0.108 & -0.028 & 0.065 \\
\hline Rep & & & & 1 & -0.073 & $0.239^{*}$ & 0.040 & -0.067 & -0.147 & $-0.238^{*}$ & $-0.269^{* *}$ & -0.137 \\
\hline EW & & & & & 1 & 0.073 & 0.191 & 0.088 & $-0.290^{* *}$ & $-0.326^{* *}$ & $-0.257^{* *}$ & -0.171 \\
\hline $\mathrm{TF}$ & & & & & & 1 & 0.032 & 0.011 & -0.043 & 0.029 & 0.183 & 0.033 \\
\hline Ins & & & & & & & 1 & $0.269^{* *}$ & $-0.376^{* * *}$ & $-0.267^{* *}$ & -0.161 & $-0.269^{* *}$ \\
\hline Del & & & & & & & & 1 & $-0.313^{* *}$ & $-0.328^{* *}$ & $-0.359^{* * *}$ & $-0.247^{*}$ \\
\hline K-BNT & & & & & & & & & 1 & $0.449^{* * *}$ & $0.331^{* *}$ & $-0.400^{* * *}$ \\
\hline SF (a) & & & & & & & & & & 1 & $0.574^{* * *}$ & $0.502^{* * *}$ \\
\hline $\mathrm{SF}(\mathrm{m})$ & & & & & & & & & & & 1 & $0.400^{* * *}$ \\
\hline $\mathrm{PF}$ & & & & & & & & & & & & 1 \\
\hline
\end{tabular}

${ }^{*} p<0.05,{ }^{* *} p<0.01,{ }^{* * *} p<0.001$. GI: global index, Sub: substitutions, WR: word reformulations, Rep: repetitions, EW: empty words, TF: time fillers, Ins: insertions, Del: delays, K-BNT: Korean version-Boston Naming Test, SF (a): semantic fluency (animal), SF (m): semantic fluency (market), PF: phonemic fluency

성(가게물건 $)(\mathrm{F}=15.968)$ 의 경우 연령 집단 간 차이가 유의한 것으로 나타났으며, 음소 유창성의 수행은 집단 간 차이가 유 의하지 않은 것으로 나타났다( $\mathrm{F}=1.682)$. 또한, $\mathrm{K}-\mathrm{BNT}$ 와 의미 유창성 과제의 사후분석을 실시한 결과 K-BNT는 연소노인과 고령노인, 중간노인과 고령노인과의 차이가 유의하였으며, 의미 유창성(동물, 가게물건) 과제는 연소노인과 중간노인, 연소노인 과 고령노인의 차이가 통계적으로 유의한 것으로 나타났다.

\section{노년층의 단어찾기 행동과 단어 이름대기 수행의 상관}

노년층의 담화산출 과제에서의 단어찾기 행동 산출 비율과 단어 이름대기 과제 수행 사이의 관련성을 살펴보기 위하여 교 육년수를 제어변수로 한 편상관분석을 실시하고, 그 결과를 Table 4에 제시하였다. 결과를 구체적으로 살펴보면, 우선 단어 이름대기 중 K-BNT의 수행은 의미 유창성, 음소 유창성 및 담 화산출 과제에서의 단어찾기 행동 중 글로벌 지수, 무의미어, 첨가와 연장과 유의한 상관을 보였다. 다음으로 의미 유창성 과제 수행은 K-BNT, 음소 유창성, 글로벌 지수, 반복, 무의미 어, 첨가, 연장과 유의한 상관이 나타났다. 마지막으로 음소 유 창성 과제의 수행은 K-BNT, 의미 유창성, 글로벌 지수, 첨가, 연장과의 상관이 유의한 것으로 나타났다.

\section{DISCUSSIONS}

본 연구에서는 연소노인부터 고령노인에 이르는 연령 집단 별 노년층을 대상으로 담화산출 과제를 활용한 단어찾기 행동 특성을 분석하여 노년층의 연령 집단에 따른 차이를 비교하고, 이러한 결과들과 대면이름대기, 구어 유창성 과제와 같은 단어 이름대기 검사 수행 사이의 관련성을 살펴보는 것을 목적으로 하였다. 결과를 종합하면 다음과 같다.

첫째, 다변량분석 결과 연령 집단에 따른 단어찾기 행동 산 출 비율에 유의한 차이가 있었으며, 이러한 차이는 글로벌 지 수, 반복, 무의미어, 첨가, 연장에서 나타났다. 우선, 단어찾기 행동의 전체적인 비율인 글로벌 지수의 차이는 노년층의 연령 증가에 따른 이름대기 능력 저하로 인하여 대화와 같은 연결발 화 상황에서 단어찾기 행동 비율이 증가한다는 기존의 연구와 일치한다. 이러한 단어찾기 행동 비율 증가는 노년층에서 나타 나는 설단현상(tip-of-the-tongue phenomenon)과 관련이 높 으며, 이러한 문제는 다양한 언어행동으로 발현되는 것으로 알 려져 있다(Schmitter-Edgecombe et al., 2000). 본 연구에서는 반복, 무의미어, 첨가, 연장의 단어찾기 행동에서 노년층 연령 집단에 따른 차이가 유의하였다. 이들 중 반복과 연장은 노년 층의 설단현상으로 인한 단어 인출의 어려움과 관련이 있으며 
(Schwartz \& Metcalfe, 2011), 무의미어와 첨가의 비율 증가는 노년층의 경우 자발화에서 불명료한 단어 사용, 애매한 참조 및 에두르기(circumlocation)가 증가한다는 기존의 연구 결과 (Obler \& Albert, 1981)와 연결지을 수 있다. 본 연구 결과와는 달리 Schmitter-Edgecombe et al.(2000)은 자발화 상황에서 연장이 거의 나타나지 않는다고 하였는데, 그들의 연구에서는 연장을 6초 이상의 쉼(pause)으로 정의하였고, 연장 기준에 대 한 조정이 필요하다고 제언하였다. 따라서 본 연구에서는 연장 의 기준을 5 초 이상으로 정의한 결과 노년층 연령 집단에 따른 차이가 나타난 것으로 사료된다. 그 밖에 연구에서는 노년층, 특히 75세 이상에서 심을 이용한 어휘접근 전략을 사용함으로 써 연장이 증가한다고 보고하고 있어(Baik, 2013; Cooper, 1990) 본 연구 결과와 맥락을 같이한다. 다음으로 단어찾기 행 동 중 대치, 단어 재구성, 삽입어는 노년층의 연령 집단 간 차이 가 유의하지 않은 것으로 나타났다. 이 중 대치와 단어 재구성 의 산출 비율은 통계적으로 유의하지는 않았으나 고령노인의 경우 연소노인이나 중간노인에 비해 오히려 산출 비율이 낮아 지는 경향을 보였다. 이는 대치나 단어 재구성은 설단 현상이 나타났을 때 원래의 의도와는 달리 진술을 바꿈으로써 단어에 접근하는 시간을 벌기 위한 일종의 단어찾기의 노력으로 고령 노인의 경우 이러한 노력 또한 제한적인 것으로 설명할 수 있 다. 이는 설단현상의 원인을 전달손실가설(transmission deficit hypothesis)로 설명하는 기존 연구에서 표적단어가 점화 전달 의 손실로 인해 인출되지 못할 경우 표적단어를 대치할 수 있 는 대안단어 역시 인출이 제한되며, 따라서 설단현상을 보이는 노년층의 경우 목표단어 뿐 아니라 대안단어의 산출 또한 감소 한다는 결과와 맥락을 같이 한다(Park et al., 2013). 즉, 고령노 인은 단어찾기의 어려움을 피하고 단어찾기를 필요로 하는 발 화를 시작하지 않음으로써 이러한 문제를 보상한다(Schmitter-Edgecombe et al., 2000). 이러한 단어찾기의 노력이 제한 되는 대신 무의미어의 사용의 증가하며, 이는 고령노인의 경우 무의미어의 산출 빈도 증가가 단어찾기 어려움의 중요한 척도 임을 시사한다. 마지막으로 삽입어 역시 노년층 연령 집단 간의 차이가 유의하지 않은 것으로 나타났는데 이와 관련해서는 삽 입어의 기능을 고려할 필요가 있다. 삽입어는 말의 앞뒤 문맥에 영향을 주지 않는 주저 표시(hesitation marker)로 다음 말을 준비하는데 필요한 시간을 벌고 발화 산출을 지연시키는 기능, 단어찾기 어려움의 표현, 문장 형성을 위한 기능( $\mathrm{Ha} \& \mathrm{Sim}$, 2008) 등을 가진다. 따라서 삽입어의 산출량만으로는 단어찾 기 행동을 분석하는 것은 큰 의미가 없으며 어떠한 기능으로 삽입어가 사용되었는가를 고려하는 것이 중요하다. 즉, 본 연구 에서 노년층이 산출한 삽입어의 경우 설단현상으로 인한 단어 찾기 어려움에 대한 표현으로 나타났을 수도 있으나 그 밖의 기
능으로 사용되었을 가능성이 있어 연령에 따른 차이가 유의하 지 않았다고 여겨진다. 이와 관련하여 이름대기에 현격한 문제 를 보이는 알츠하이머형 치매(dementia of Alzheimer's type) 환자의 삽입어 비율이 일반 노년층과 비교하여 차이가 유의하 지 않았다는 기존의 연구 결과(Ha et al., 2009)는 본 연구 결 과와 일맥상통한다. 또한, 연령 집단 간 유의한 차이를 보였던 단어찾기 행동의 산출 비율이 어느 집단 간의 차이에 기인하였 는지 알아보기 위하여 사후분석을 실시한 결과 글로벌 지수, 무의미어, 첨가는 연소노인과 중간노인, 연소노인과 고령노인의 차이가 유의하였으며, 반복은 연소노인과 고령노인, 중간노인 과 고령노인과의 차이가, 마지막으로 연장은 연소노인과 고령노 인의 차이만 통계적으로 유의한 것으로 나타났다. 이러한 사후 분석의 결과는 다양한 단어찾기 행동의 노화로 인한 변화가 드 러나는 시기가 서로 다름을 시사한다.

둘째, 연소노인, 중간노인, 고령노인의 연령 집단에 따른 단어 이름대기 과제 수행의 차이 또한 통계적으로 유의한 것으로 나 타났다. 단어 이름대기 과제별 수행 차이를 살펴보면 K-BNT, 의미 유창성 과제는 연령 집단 간 차이가 유의한 것으로 나타났 으며, 음소 유창성의 수행은 집단 간 차이가 유의하지 않은 것 으로 나타났다. 이러한 결과는 임상에서 많이 사용하는 단어 수준의 이름대기 과제 역시 연령 증가에 따른 이름대기 수행의 손상을 적절히 반영함을 시사한다. 다만, K-BNT와 의미 유창 성 과제의 사후분석 결과 상대적으로 학력이 높았던 연소노인 과 다른 집단의 차이는 유의하였으나 중간노인과 고령노인 사 이의 차이는 유의하지 않았다. 이와 관련하여 일부 연구자들은 이러한 단어 이름대기 검사들이 연령에 따른 정확도의 차이를 변별하기에는 제한적이며(Mortensen et al., 2006), 고학력자들 의 경우 이러한 검사들의 민감도가 낮다고 주장한다(Connor et al., 2004). 기존의 연구 결과와는 달리 음소 유창성 과제의 수 행은 연령 집단에 따른 차이가 유의하지 않았는데, 이는 본 연 구에서 교육년수를 통제한 상태에서 이름대기 능력을 평가했기 때문에 나타난 결과라고 여겨진다. 즉, 첫 음소(자소)를 제시하 고 해당 음소로 시작하는 단어를 나열해야 하는 음소 유창성의 경우 의미 유창성에 비해 교육정도에 의한 영향이 크기 때문에 (Ratcliff et al., 1998) 교육정도를 통제한 본 연구의 결과에서 연령에 따른 차이가 상쇄되었을 것으로 생각할 수 있다.

마지막으로 노년층의 담화산출 과제에서의 단어찾기 행동 산출 비율과 단어 이름대기 과제 수행 사이의 관련성을 살펴보 기 위하여 상관분석을 실시한 결과 단어 이름대기 중 K-BNT 의 수행은 의미 유창성, 음소 유창성 및 담화산출 과제에서의 단어찾기 행동 중 글로벌 지수, 무의미어, 첨가, 연장과 유의한 상관을 보였다. 다음으로 의미 유창성 과제 수행은 K-BNT, 음 소 유창성, 글로벌 지수, 반복, 무의미어, 첨가, 연장과 유의한 상 
관이 나타났다. 마지막으로 음소 유창성 과제의 수행은 K-BNT, 의미 유창성, 글로벌 지수, 첨가, 연장과의 상관이 유의한 것으로 나타났다. 이러한 결과는 담화산출 과제에서 나타난 단어찾기 행동의 글로벌 지수 및 반복, 무의미어, 첨가, 연장의 산출 비율 이 일반적인 이름대기 과제의 수행과 관련이 있음을 알 수 있다. 단어 이름대기 과제와 상대적으로 가장 높은 상관을 보인 항목 은 단어찾기 행동의 전체적인 산출 비율인 글로벌 지수로 나타 났는데, 이를 통하여 단어 이름대기와 담화산출 과제 모두 노년 층의 단어 산출의 어려움을 잘 반영한다고 생각할 수 있다. 또 한, 구체적인 단어찾기 행동 중 단어 이름대기와 공통적으로 유 의한 상관이 나타난 변수는 무의미어, 첨가, 연장이었는데, 이러 한 단어찾기 행동은 연령에 따라 산출 비율 또한 증가하였다. 이는 이러한 단어찾기 행동들이 노화에 따른 이름대기 능력의 변화를 파악하는데 중요한 변수임을 시사한다.

본 연구는 노년층의 단어 산출의 문제가 나타나는 자연스러 운 환경에서 다양한 행동을 분석했다는 점에서 임상적인 의의 를 가진다. 담화를 이용한 단어찾기 문제를 평가하는 것은 다음 과 같은 유용성을 가진다. 첫째, 대상자가 실제로 단어찾기에 문 제를 보이는 자연스러운 환경에서 이름대기 평가를 실시할 수 있다. 둘째, 다양한 유형의 단어찾기 오류를 동시에 효율적으로 평가할 수 있기 때문에 문제해결 방법에 더 쉽게 접근할 수 있 다. 실제로 담화를 이용한 이름대기 치료는 많은 연구에서 그 효과가 입증되었다(Marks \& Stokes, 2010). 그러나 담화를 이용 한 단어찾기 능력을 평가하는 것은 단어 이름대기 과제에 비해 분석을 위한 많은 시간과 노력을 필요로 한다는 단점을 가진다. 이러한 한계를 극복하기 위하여 German(1991)에 의해 개발된 아 동용 TWFD처럼 노년층를 위한 담화에서의 단어찾기 행동을 평 가할 수 있는 표준화된 검사의 개발이 필요하다. 실제로 TWFD 검사의 유용성을 평가하기 위한 판별분석 결과 이름대기에 어려 움을 가진 아동들을 $90 \%$ 이상 정확히 검출 가능하였다 $(\mathrm{Ger}-$ man \& Glasnapp, 1990). 또한, 노년층의 이름대기 문제를 검출 하기 위한 그림설명 과제의 유용성을 검증했다는 점도 추가적 인 의의로 들 수 있다. 그림설명 과제는 주어진 그림을 설명하는 과제로 대상자 사이에 어느 정도의 객관적인 비교가 가능하고 인지적 부담감이 크지 않아 노년층의 단어찾기 문제 및 단어찾 기를 위한 다양한 노력을 자연스럽게 평가하는 것이 가능하다 (Baik, 2013; Ha et al., 2009). 다만, 연구 대상이 된 일반 노년 층의 선정 시 신경심리검사를 통하여 보다 면밀히 인지기능을 평가하지 못한 점이 아쉬움으로 남는다. 앞으로는 노년층을 위 한 담화에서의 단어찾기 행동을 평가할 수 있는 표준화된 검사 의 개발 등 다양한 후속연구가 진행되기를 바란다.

중심 단어 : 담화산출·노년층·이름대기·단어찾기 행동.

\section{Ethical Statement}

This study was approved by the Institutional Review Board of Korea Nazarene University (IRB-2019-2-17).

\section{Acknowledgments}

N/A

\section{Declaration of Conflicting Interests}

There are no conflict of interests.

\section{Funding}

This research was supported by the Korea Nazarene University Research Grants 2020.

\section{ORCID iD}

Hyunjoo Choi https://orcid.org/0000-0003-4654-3206

\section{REFERENCES}

Baik, M. A. (2013). Traits of word retrieval behavior in healthy Korean elderly (Unpublished master's thesis). Yonsei University, Seoul.

Baldo, J. V., Schwartz, S., Wilkins, D., \& Dronkers, N. F. (2006). Role of frontal versus temporal cortex in verbal fluency as revealed by voxelbased lesion symptom mapping. Journal of the International Neuropsychological Society, 12(6), 896-900.

Boyle, M. (2014). Test-retest stability of word retrieval in aphasic discourse. Journal of Speech, Language, and Hearing Research, 57(3), 966-978.

Bruda, A. N. (2010). Communication and Swallowing Changes in Healthy Aging Adults. Sudbury, MA: Jones and Bartlett Learning.

Cheung, H. \& Kemper, S. (1992). Competing complexity metrics and adults' production of complex sentences. Applied Psycholinguistics, 13(1), 53-76.

Cho, M.J., Bae, J. N., Suh, G. H, Hahm, B. J., Kim, J. K., Lee, D. W., et al. (1999). Validation of Geriatric Depression Scale, Korean version (GDS) in the assessment of DSM-III-R major depression. Journal of Korean Neuropsychiatric Association, 38(1), 48-63.

Choi, H. (2014). The relationship between demographic factors and expressive language ability to correct information units in healthy senior citizens. Journal of Speech-Language and Hearing Disorders, 23(3), 51-60.

Connor, L. T., Spiro, A., 3rd, Obler, L. K., \& Albert, M. L. (2004). Change in object naming ability during adulthood. The Journals of Gerontology. Series B, Psychological Sciences and Social Sciences, 59(5), P203-P209.

Cooper P. V. (1990). Discourse production and normal aging: Performance on oral picture description tasks. Journal of Gerontology, 45(5), P210P214.

Duong, A., Tardif, A., \& Ska, B. (2003). Discourse about discourse: What is it and how does it progress in Alzheimer's disease? Brain and Cognition, 53(2), 177-180.

Faust, M., Dimitrovsky, L., \& Davidi, S. (1997). Naming difficulties in language-disabled children: Preliminary findings with the application of the tip-of-the-tongue paradigm. Journal of Speech, Language, and Hearing Research, 40(5), 1026-1036.

German, D. J. (1991). Test of Word Finding in Discourse TWFD: Administration, Scoring, Interpretation, and Technical Manual. Austin, TX: Pro-Ed.

German, D. J. \& Glasnapp, D. R. (1990). The test of word-finding in discourse: Diagnostic utility evidence. Educational and Psychological Measurement, 50(2), 383-392.

Goodglass, H., Kaplan, E., \& Barresi, B. (2001). BDAE-3: Boston Diagnostic Aphasia Examination. (3rd ed.). Philadelphia, PA: Lippincott Williams \& Wilkins.

Goulet, P., Ska, B., \& Kahn, H. J. (1994). Is there a decline in picture naming with advancing age? Journal of Speech and Hearing Research, 37(3), 629-644.

Ha, J. W., Jung, Y. H., \& Sim, H. S. (2009). The functional characteristics of fillers in the utterances of dementia of Alzheimer's type, question- 
able dementia, and normal elders. Communication Sciences and Disorders, 14(4), 514-530.

Ha, J. W. \& Sim, H. S. (2008). A comparison study of interjectional characteristics between people who stutter and people who do not stutter. Communication Sciences and Disorders, 13(3), 438-453.

Heller, R. B. \& Dobbs, A. R. (1993). Age differences in word finding in discourse and nondiscourse situations. Psychology and Aging, 8(3), 443450 .

Hummert, M. L., Garstka, T. A., Shaner, J. L., \& Strahm, S. (1995). Judgments about stereotypes of the elderly: Attitudes, age associations, and typicality ratings of young, middle-aged, and elderly adults. Research on Aging, 17(2), 168-189.

Jin, C., Choi, H., \& Lee, J. Y. (2016). Usefulness of spontaneous speech analysis scales in patients with mild cognitive impairment and dementia of Alzheimer's type. Communication Sciences and Disorders, 21(2), 284294.

Kang, Y. (2006). A normative study of the Korean-Mini Mental State Examination (K-MMSE) in the elderly. Korean Journal of Psychology, 25(2), $1-12$.

Kang, Y., Chin, J., Na, D. L., Lee, J., \& Park, J. S. (2000). A normative study of the Korean version of Controlled Oral Word Association Test (COWAT) in the elderly. Korean Journal of Clinical Psychology, 19(2), 385-392.

Kaplan, E. F., Goodglass, H., \& Weintraub, S. (1983). The Boston Naming Test. (2nd ed.). Philadelphia, PA: Lea \& Febiger.

Kim, H., Heo, J. H., Kim, D. Y., \& Kim, J. W. (2009). Screening Test for Aphasia and Neurologic-Communication Disorders. Seoul: Hakjisa.

Kim, H. \& Na, D. (1997). Korean Version-Boston Naming Test (K-BNT). Seoul: Hakjisa.

Kim, H. \& Na, D. (2001). Paradise-Korean Version-Western Aphasia Battery (K-WAB). Seoul: Paradise Welfare Foundation.

Kim, J. \& Kim H. (2009). Communicative ability in normal aging: A review. Communication Sciences and Disorders, 14(4), 495-513.

Kim, J. M., Yoon, M. S., Kim, S. J., Chang, M. S., \& Cha, J. (2012). Utterance types in typically developing preschoolers. Communication Sciences and Disorders, 17(3), 488-498.
Marks, I. \& Stokes, S. F. (2010). Narrative-based intervention for word-finding difficulties: A case study. International Journal of Language and Communication Disorders, 45(5), 586-599.

Mortensen, L., Meyer, A. S., \& Humphreys, G. W. (2006). Age-related effects on speech production: A review. Language and Cognitive Processes, 21(1-3), 238-290.

Neugarten, B. L. (1974). Age groups in American society and the rise of the young-old. The ANNALS of the American Academy of Political and Social Science, 415(1), 187-198.

Obler, L. K. \& Albert, M. L. (1981). Language and aging: A neurobehavioral analysis. In Beasley, D. S. \& Davis, G. A. Aging: Communication Process and Disorders (pp.110-111). New York, NY: Grune and Stratton.

Orange, J. B. \& Purves, B. (1996). Conversational discourse and cognitive impairment: Implications for Alzheimer's disease. Journal of SpeechLanguage, Pathology and Audiology, 20(2), 139-150.

Park, J., Lee, K. E., \& Lee, H. W. (2013). The effects of aging on retrieval of phonological knowledge in Korean: The tip-of-the-tongue phenomenon in young and older adults. Korean Journal of Cognitive Science, 24(2), 111-132.

Ratcliff, G., Ganguli, M., Chandra, V., Sharma, S., Belle, S., Seaberg, E., et al. (1998). Effects of literacy and education on measures of word fluency. Brain and Language, 61(1), 115-122.

Schmitter-Edgecombe, M., Vesneski, M., \& Jones, D. W. (2000). Aging and word-finding: A comparison of spontaneous and constrained naming tests. Archives of Clinical Neuropsychology, 15(6), 479-493.

Schwartz, B. L. \& Metcalfe, J. (2011). Tip-of-the-tongue (TOT) states: Retrieval, behavior, and experience. Memory and Cognition, 39(5), 737-749.

Tingley, S. J., Kyte, C. S., Johnson, C. J., \& Beitchman, J. H. (2003). Singleword and conversational measures of word-finding proficiency. American Journal of Speech-Language Pathology, 12(3), 359-368.

Verhaegen, C. \& Poncelet, M. (2013). Changes in naming and semantic abilities with aging from 50 to 90 years. Journal of the International Neuropsychological Society, 19(2), 119-126.

Yi, B. W. (2015). Korean Grammar for Speech-Language Pathologists. Seoul: Hakjisa. 
APPENDIX

\section{단어찾기 행동과 예시}

\begin{tabular}{|c|c|c|}
\hline 단어찾기 행동 & 설 명 & 예 시 \\
\hline 글로벌 지수(Global index) & $\begin{array}{l}\text { 전체 어절 중 아래의 일곱 가지의 특정 단어찾기 } \\
\text { 행동을 포함한 어절의 비율 }\end{array}$ & - \\
\hline \multicolumn{3}{|l|}{$\begin{array}{l}\text { 특정 단어찾기 행동 } \\
\text { (specific word finding) }\end{array}$} \\
\hline 대치(substitutions) & 단어찾기에 실패한 목표단어를 다른 단어로 바꿈 & 책상(의자)을 가져와서 $\cdots$ \\
\hline $\begin{array}{l}\text { 단어재구성 } \\
\text { (word reformulations) }\end{array}$ & 사용한 단어를 변경, 수정함 & 여자가, 엄마가 설거지를 $\cdots$ \\
\hline 반복(repetitions) & 음절, 단어, 구를 반복함 & 과자, 과자를 $\cdots$ \\
\hline 무의미어(empty words) & $\begin{array}{l}\text { 그림설명 내용에 포함되지 않거나 특정되지 않는 } \\
\text { 단어 등이 나타남 }\end{array}$ & 거기, 동생은 과자를 꺼내고 $\cdots$ \\
\hline 삽입어(time fillers) & $\begin{array}{l}\text { 그림설명의 앞뒤 문맥에 영향을 주지 않는 모음이나 } \\
\text { 음절 등의 발화 행동이 나타남 }\end{array}$ & 접시를 닦고, 어, 음, 싱크대 위에 $\cdots$ \\
\hline 첨가(insertions) & 담화산출에 자신의 생각 등이 첨가됨 & 여기 엄마가 $\cdots$ 이거 이름을 뭐라고 하더라? \\
\hline 연장(delays) & $\begin{array}{l}\text { 5초 이상의 연장된 쉼(pause)이 담화산출 과정에서 } \\
\text { 나타남 }\end{array}$ & 엄마가 $\cdots(5$ 초 $) \cdots$ 접시를 닦고 있네 \\
\hline
\end{tabular}

